\title{
Effect of SPT Hammer Energy Efficiency in the Bearing Capacity Evaluation in Sands
}

\author{
Indrasenan Thusyanthan, Bassim A. Nawaz \\ Saudi Aramco, Consulting Services Department \\ Dhahran, Saudi Arabia
}

\begin{abstract}
Geotechnical investigation plays a vital role in all projects as the subsurface soil conditions at the project site determine the required site preparation and foundation sizes. Data from Standard Penetration Testing (SPT), the most common form of field testing in geotechnical investigations, is often correlated to soil properties for the evaluation of Net Allowable Bearing Capacity (NABC). The $\mathrm{NABC}$ of the project site is critical for the project as this value determines foundation sizes and whether soil improvement is required. The energy efficiency of an SPT hammer is fundamental to obtaining the correct SPT test data. While older SPT hammers, which are manually operated, may have an energy efficiency close to $60 \%$, newer SPT hammers are often automatic and have much higher energy efficiencies. As the majority of correlations between SPT data and soil properties, which lead to NABC in geotechnical engineering, were developed based on SPT data from manual SPT hammers with energy efficiencies close to $60 \%$, it is mandatory to normalise SPT data from higher energy efficiency hammers to that from $60 \%$ energy efficient hammers. The practice of using SPT test data without proper energy efficiency correction still exits around the world. Such use of SPT test data leads to unreliable soil bearing capacity and, in case of automatic SPT hammers, this can lead to increased project cost due to larger foundations and unnecessary soil improvement costs. This paper presents insight into such issues and how to ensure correct use of SPT test data and evaluation of soil bearing capacity.
\end{abstract}

Keywords: geotechnical investigation, SPT testing, soil bearing capacity, boreholes

\section{Introduction}

Geotechnical engineering plays a vital role in any project as the subsurface soil conditions at the project site determine the duration and costs associated with site preparation and type and sizes of foundations to be used. Geotechnical investigation involves borehole testing and collecting soil samples for laboratory testing. A Standard Penetration Test (SPT) is the most commonly used in-situ testing for evaluating in-situ soil properties, $[1,5]$. The main output of the SPT test is "N" values, which are used to obtain soil properties by correlations. The SPT test involves dropping in a weight (hammer of $140 \mathrm{lb}$ ) a set distance (30in) onto a sampler within the borehole (Figure 1). This drop is counted as single blow count. The number of blows required for the sampler to advance or penetrate the last $300 \mathrm{~mm}$ (12 in) after a full $450 \mathrm{~mm}$ penetration is referred to as the $\mathrm{N}$ value. This $\mathrm{N}$ value depends mainly on soil properties but it also depends on the SPT hammer details such as efficiency of hammer, borehole diameter, sampler type, and rod length.

Numerous correlations between SPT data and soil properties in geotechnical engineering were developed based on SPT data from manual SPT hammers with hammer efficiencies close to 60\%. Furthermore, variations in N-values of $100 \%$ or more have been observed ([6] \& ASTM D1586-99) when using different standard penetration test apparatus and drillers for adjacent borings in the same soil formation. It is vital that energy efficiency measurement for a specific SPT hammer is undertaken, as recommended by ASTM D-4633 [2], and SPT N number is normalized to that of SPT hammer with energy efficiency of $60 \%$ to ensure the effect of SPT hammer does not affect the interpreted soil properties. Therefore, SPT hammer efficiency shall be measured and used to correct the SPT N value. The resulting number is known as N60. The corresponding N60 value is then used to obtain soil properties such as friction angle, which in turn is used for the evaluation of allowable bearing capacity calculation. 
The SPT N number is normalized to a hammer with energy efficiency of 60\%, known as N60:

$$
N_{60}=\frac{N \cdot C_{1} \cdot C_{2} \cdot C_{3} \cdot C_{4}}{60}
$$

Where;

- $\mathrm{C}_{1}=$ hammer efficiency $(\%)$

- $\mathrm{C}_{2}=$ correction for borehole diameter

- $\mathrm{C}_{3}=$ sampler correction

- $\mathrm{C}_{4}=$ correction for rod length

Geotechnical literature, [4], recommended $\mathrm{C}_{2}, \mathrm{C}_{3}$ and $\mathrm{C}_{4}$ are provided in Table 1 . The $\mathrm{C}_{1}$ (hammer efficiency) depends on the hammer type and cannot be obtained without energy efficiency measurement of the SPT hammer. Note that liquefaction assessment requires the SPT $\mathrm{N}$-value to be corrected for overburden pressure in addition to the standard corrections. $\mathrm{N}_{60}$ values corrected by a correction factor for overburden is denoted as $\mathrm{N}_{1(60) \text {. }}$.

$$
\begin{gathered}
\left(N_{1}\right)_{60}=C_{N} \cdot N_{60} \\
C_{N}=\min \left[1.5, \sqrt{\frac{98}{\sigma^{\prime}}}\right]
\end{gathered}
$$

Equation 3 is from BS EN ISO 22476-3:2005, [3] and $\sigma^{\prime}$ is vertical effective overburden in $\mathrm{kPa}$.

Table 1: Recommended Correction Factors to obtain $\mathrm{N}_{60}$.

\begin{tabular}{|c|c|}
\hline & Correction Factor \\
\hline Borehole Diameter & $\mathbf{C}_{\mathbf{2}}$ \\
\hline $60-120 \mathrm{~mm}$ & 1 \\
\hline $150 \mathrm{~mm}$ & 1.05 \\
\hline $200 \mathrm{~mm}$ & 1.15 \\
\hline Sampler & $\mathbf{C}_{\mathbf{3}}$ \\
\hline With liner: Loose sand & 0.8 \\
\hline With Liner: Dense sand, Clay & 0.9 \\
\hline Without Liner & 1 \\
\hline Rod Length & $\mathbf{C}_{\mathbf{4}}$ \\
\hline 0 to $4 \mathrm{~m}$ & 0.75 \\
\hline 4 to $6 \mathrm{~m}$ & 0.85 \\
\hline 6 to $10 \mathrm{~m}$ & 0.95 \\
\hline 10+ & 1 \\
\hline
\end{tabular}

\section{SPT Hammer Energy Efficiency Measurement}

As per section 7.4 of ASTM 1586, [1], the energy delivered to the drill rod can be measured according to procedures in Test Method D4633, [2]. Annex B of BS EN ISO 22476-3:2005 +A1:2011 (Geotechnical Investigation and Testing Field Testing, Part 3: Standard Penetration Test) also provides recommended method to measure the actual energy delivered to the SPT hammer.

Traditionally, the SPT hammers that were used in the Kingdom of Saudi Arabia did not have energy efficiency certificates but were assumed to have 60\% energy efficiency. In 2016, the energy efficiency of all automatic SPT 
hammers in use in the Kingdom of Saudi Arabia for Saudi Aramco were tested. As seen in Figure 1, the energy efficiency of SPT hammers are mostly in the range of 80 to $100 \%$ with an average of $86 \%$ for 51 hammers tested.

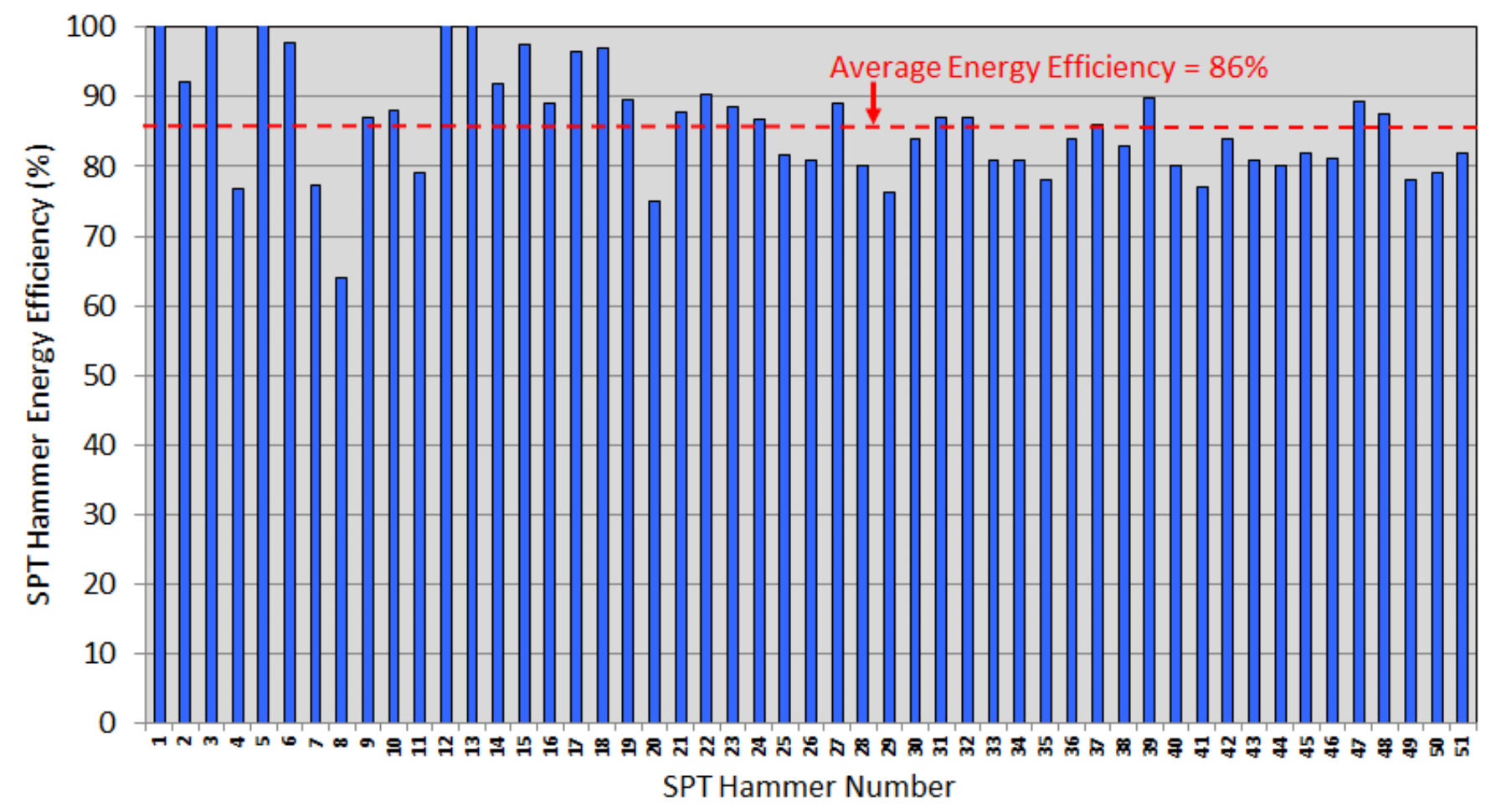

Fig. 1: Energy efficiency data of automatic SPT hammers in the Kingdom of Saudi Arabia.

\section{Effect of SPT Hammer Energy Efficiency}

\subsection{Effect of SPT Hammer Energy Efficiency in SPT Data}

SPT hammer efficiency plays a critical role in the SPT N value obtained in geotechnical investigations. The lower the energy efficiency of a hammer, the higher the number of blows required to move the SPT sampler by $300 \mathrm{~mm}$, resulting in a higher SPT N number. For the same soil conditions, a SPT hammer with lower energy efficiency would result in a higher SPT N number than that from a higher energy efficiency SPT hammer. Therefore, any interpretation of soil properties based on SPT N is highly dependent on the SPT hammer and would not reflect the true soil properties. This is demonstrated in Fig. 2 by a hypothetical example. Let us assume two SPT hammers with $60 \%$ and $90 \%$ energy efficiencies were used to obtain SPT N values at the same soil location. The results would be as per Fig. 2, which highlights the difference in SPT $\mathrm{N}$ from two hammers for the same soil. If SPT $\mathrm{N}$ values were normalized to $\mathrm{N}_{60}$ as per Equation 1, then the SPT $\mathrm{N}_{60}$ value (10) would be the same for data from both the hammers. This demonstrates that uncorrected SPT N values should not be used for any interpretation soil properties, as it would be misleading. Therefore, any soil property interpretation from SPT data needs to be independent of the hammer, and this is only possible if the energy efficiency of the SPT hammer is known and the data is normalized to $\mathrm{N}_{60}$. 


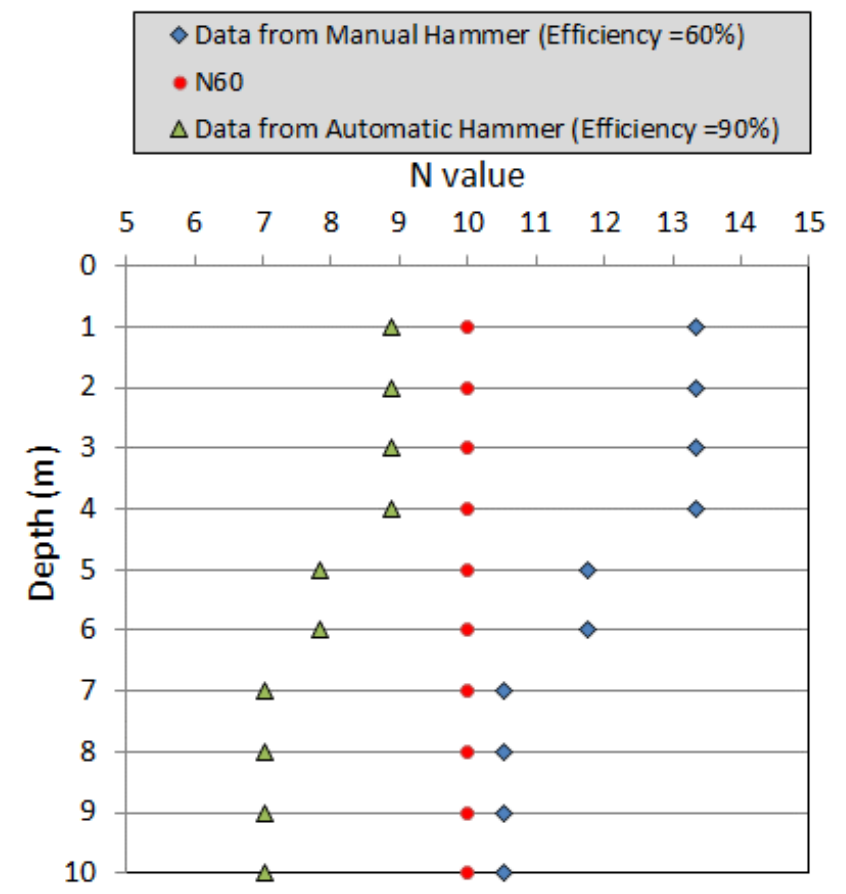

Fig. 2: Effect of SPT hammer energy efficiency in the SPT N data.

\subsection{Effect of SPT Hammer Energy Efficiency in Evaluation of Bearing Capacity in Sand}

It is common practice in the Kingdom of Saudi Arabia to utilize the SPT data from sand directly to evaluate friction angle of sands and then evaluate the allowable bearing capacity based on the friction angle and foundation details. The steps to be followed for the evaluation of the bearing capacity from time of in-situ testing is provided in Fig.3. SPT data is from in-situ testing is corrected using the SPT hammer energy efficiency to obtain N60 values. The friction angle of the sand can then be obtained using corrections such as provided in equation (4) as per $[4,9]$.

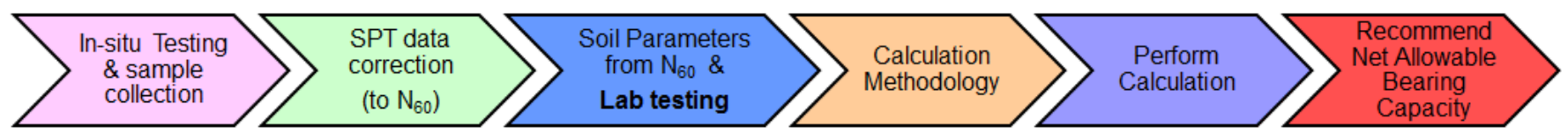

Fig. 3: Steps for evaluation of soil bearing capacity.

Based on contractor submitted SPT hammer efficiency certificates, it can be concluded that majority of the automatic hammers used by geotechnical contractors all have energy efficiencies in the rage 80 to $100 \%$ with an average of $86 \%$. This is significantly higher than the $60 \%$ energy efficiency that is commonly assumed by geotechnical contractors.

$$
\phi(\operatorname{deg})=27.1+0.3 N_{60}-0.00054\left[N_{60}\right]^{2}
$$

The below example shows the benefit of utilizing correct hammer efficiency in evaluating Net Allowable Bearing Capacity (NABC in sands. An example is undertaken for a hammer, which had measured energy efficiency of $90 \%$ as shown in Fig. 4. The NABC is evaluated in two ways;

1. Method 1 - Assuming 60\% hammer efficiency (which was common practice in Kingdom prior to 2016) leading to Answer A1.

2. Method 2 - Utilizing the correct measured energy efficiency, leading to answer B1. 


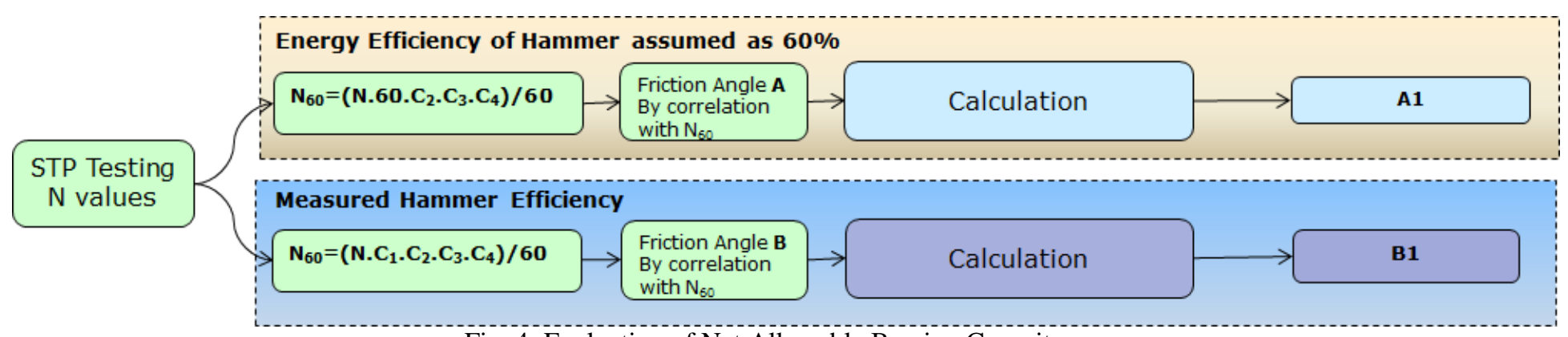

Fig. 4: Evaluation of Net Allowable Bearing Capacity.

Example:

Evaluation of NABC for a $2 \mathrm{~m}$ by $2 \mathrm{~m}$ foundation at $1 \mathrm{~m}$ depth. The SPT test data at a sand site results in N=15 and NABC is required. A time factor is not considered in the settlement calculations.

The NABC is limited by either the shear failure or settlement criteria. The shear limit can be obtained by equation (5) (as per reference [7]). The drained $\operatorname{NABC}\left(\mathrm{q}_{\mathrm{a}(\mathrm{net})}\right)$ of shallow foundations shall be calculated based on the equation (5) below.

$$
\mathrm{q}_{\mathrm{A}(\mathrm{net})}=\frac{1}{\mathrm{~F}}\left[\mathrm{qs}_{\mathrm{q}} \mathrm{N}_{\mathrm{q}}+\frac{\gamma^{\prime}}{2} \mathrm{Bs}_{\gamma} \mathrm{N}_{\gamma}\right]-\gamma^{\prime} \mathrm{D}
$$

Where B is the foundation width, $\mathrm{D}$ is the foundation embedment, $\gamma$, is the effective unit weight of the soil and $\mathrm{q}$ vertical stress at the foundation base level $\left(\gamma^{\prime} \mathrm{D}\right)$. Factor of safety $(\mathrm{F})$ to be 3 .

$$
N_{q}=\tan ^{2}\left[45+\frac{\phi}{2}\right] e^{\pi \tan \phi}, \quad N_{\gamma}=2\left[N_{q}+1\right] \tan \phi, \quad s_{q}=\left[1+\frac{B}{L} \tan \phi\right], \quad s_{\gamma}=\left[1-0.4 \frac{B}{L}\right]
$$

Settlement calculation are based on the Burland and Burbrige method [8] is limited to $25 \mathrm{~mm}$ and in this example no time factor is considered for simplicity. In normal calculations, the time factor shall be considered relevant to the project requirements.

Method 1 - Assuming Energy Efficiency of SPT hammer as $60 \%$.

For a $\mathrm{N}=15$ with energy efficiency as $60 \%$, we would obtain $\mathrm{N}_{60}$ as 11.3 (Table 2), which leads to a friction angle of 30.4 as per equation (4). Therefore, the calculated NABC is $250 \mathrm{kPa}$ for a $2 \mathrm{~m} \mathrm{x} 2 \mathrm{~m}$ with $25 \mathrm{~mm}$ settlement limit.

Method 2- Utilized the Measured Energy Efficiency of SPT hammer, which is $90 \%$.

For a $\mathrm{N}=15$ with energy efficiency as $90 \%$, we would obtain $\mathrm{N}_{60}$ as 16.9 (Table 2), which leads to friction angle of 32 as per equation (4). Therefore, the calculated NABC would be $320 \mathrm{kPa}$.

The above exercise shows the importance of using the correct energy efficiency value for evaluation of NABC. The results are summarized in Table 3, which clearly highlights that if energy efficiency of $60 \%$ had been used for automatic SPT hammers, then the evaluated soil bearing capacity would have been an under-prediction by 30-60 percent for SPT values in the range of 10-15.

Table 2: $\mathrm{N}_{60}$ from $\mathrm{N}$ for Energy Efficiency of $60 \%$ and $90 \%$.

\begin{tabular}{|c|c|c|c|c|c|c|}
\hline Depth (m) & $\mathrm{N}$ & $\mathrm{C}_{4}$ & $\mathrm{C}_{3}$ & $\mathrm{C}_{2}$ & $\mathrm{C}_{1}$ & $\mathrm{~N}_{60}$ \\
\hline 1 & 15 & 0.75 & 1 & 1 & 60 & 11.3 \\
\hline 2 & 15 & 0.75 & 1 & 1 & 60 & 11.3 \\
\hline 3 & 15 & 0.75 & 1 & 1 & 60 & 11.3 \\
\hline 4 & 15 & 0.75 & 1 & 1 & 60 & 11.3 \\
\hline
\end{tabular}




\begin{tabular}{|c|c|c|c|c|c|c|}
\hline Depth (m) & $\mathrm{N}$ & $\mathrm{C}_{4}$ & $\mathrm{C}_{3}$ & $\mathrm{C}_{2}$ & $\mathrm{C}_{1}$ & $\mathrm{~N}_{60}$ \\
\hline 1 & 15 & 0.75 & 1 & 1 & 90 & 16.9 \\
\hline 2 & 15 & 0.75 & 1 & 1 & 90 & 16.9 \\
\hline 3 & 15 & 0.75 & 1 & 1 & 90 & 16.9 \\
\hline 4 & 15 & 0.75 & 1 & 1 & 90 & 16.9 \\
\hline
\end{tabular}

Table 3: Effect of Hammer Energy Efficiency on the NABC.

\begin{tabular}{|c|c|c|c|}
\hline \multirow{2}{*}{ Uncorrected SPT } & Hammer Energy & $\begin{array}{c}\text { Net Allowable Bearing Capacity } \\
2 \mathrm{~m} \times 2 \mathrm{~m} \text { foundation at 1 m depth }\end{array}$ & $\begin{array}{c}\text { Percentage } \\
\text { increase in } \\
\text { NABC }\end{array}$ \\
\hline \multirow{2}{*}{ SPT N $=10$} & $60 \%$ (assumed) & $150 \mathrm{kPa} \quad$ (under-estimate) & \\
\cline { 2 - 4 } & $90 \%$ (measured) & $250 \mathrm{kPa}$ (correct value) & $66 \%$ \\
\hline \multirow{2}{*}{ SPT N =15 } & $60 \%$ (assumed) & $250 \mathrm{kPa}$ (under-estimate) & \\
\cline { 2 - 4 } & $90 \%$ (measured) & $320 \mathrm{kPa}$ (correct value) & $28 \%$ \\
\hline
\end{tabular}

\section{Benefits of using Correct Energy Efficiency of SPT Hammer}

It is demonstrated in the previous section that using correct Energy Efficiency Corrected SPT data for the evaluation of bearing capacity would provide 30\% -60\% higher bearing capacity than that would be calculated by assumed $60 \%$ hammer efficiency for automatic hammers. The benefit of the utilizing corrected SPT data on a project can be understood with example shown in Fig. 5. Let us assume that project requirement is $200 \mathrm{kPa}$ bearing capacity.

- For a raw SPT (uncorrected) data of $\mathrm{N}=10$, use of incorrect hammer efficiency would result in recommendation of $150 \mathrm{kPa}$ as NABC for a $2 \mathrm{~m} \times 2 \mathrm{~m}$ foundation at $1 \mathrm{~m}$ depth. The conclusion would have been that piling foundation or soil improvement is required for the project. This would lead to unnecessary cost and time delay for the project as the correct bearing capacity is $250 \mathrm{kPa}$ as noted below.

- For a raw SPT (uncorrected) data of $\mathrm{N}=10$, use of correct energy efficiency correction would lead to recommendation of $250 \mathrm{kPa} \mathrm{NABC}$ for a $2 \mathrm{~m} \times 2 \mathrm{~m}$ foundation at $1 \mathrm{~m}$ depth. The conclusion would be that shallow foundation is acceptable and that no pile foundation or soil improvement required, saving cost and time for the project.

\section{Net Allowable Bearing Capacity}

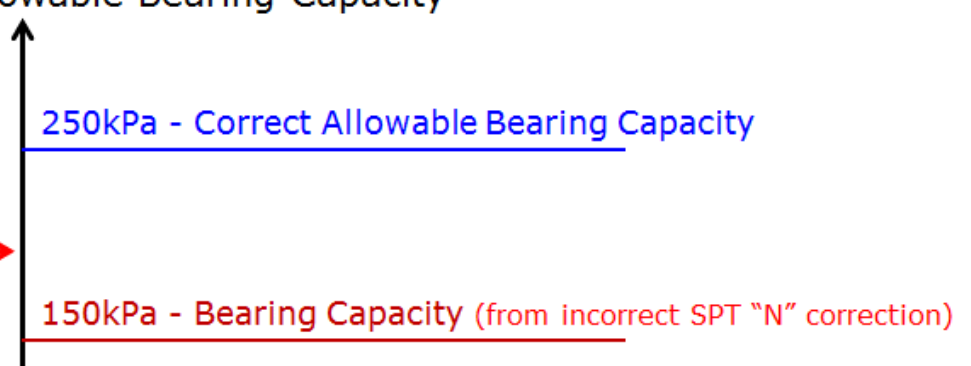

Incorrect SPT data would
to conclusion that "soil

improvement required",

costing $\$ \$ \$$ millions to Project

$>$ No Soil improvement required based on Corrected SPT data

Fig. 5: Benefit of using energy corrected SPT N to evaluate NABC. 


\section{Conclusion}

The geotechnical engineering literature has numerous correlations based on SPT N-values based on SPT N-values obtained with manual SPT hammers (cathead and drop hammer methods). SPT N-values used in these correlations do not take into account the effect of newer equipment features that influence the actual amount of energy imparted during the SPT. The manual hammers typically deliver energy at an estimated average efficiency of $60 \%$. Nowadays, automatic hammers deliver energy at a significantly higher efficiency (80-100\%). To ensure correct use of correlations developed using manual hammers, the SPT N-values from automatic hammers shall be corrected to $\mathrm{N}_{60}$ prior to the use of correlations.

This paper highlighted the importance of utilizing correct SPT hammer energy efficiency in normalizing SPT test data. Use of incorrect energy efficient calibration to obtain $\mathrm{N}_{60}$ leads to incorrect soil relative density description and unreliable soil bearing capacity. Assuming energy efficiency as $60 \%$ for automatic SPT hammer in bearing capacity evaluations will leads to under-prediction of soil bearing capacity, which in turn can lead to increased projects costs and time due to unnecessary soil improvements and larger foundations. Therefore, it can be concluded that the energy efficiency of SPT hammers are critical in all geotechnical investigations and any soil property correlation with SPT testing shall be based on correct $\mathrm{N}_{60}$ values. Fig. 6 below summarizes the correct methodology to use SPT data in interpreting soil properties and in evaluation of soil bearing capacity.

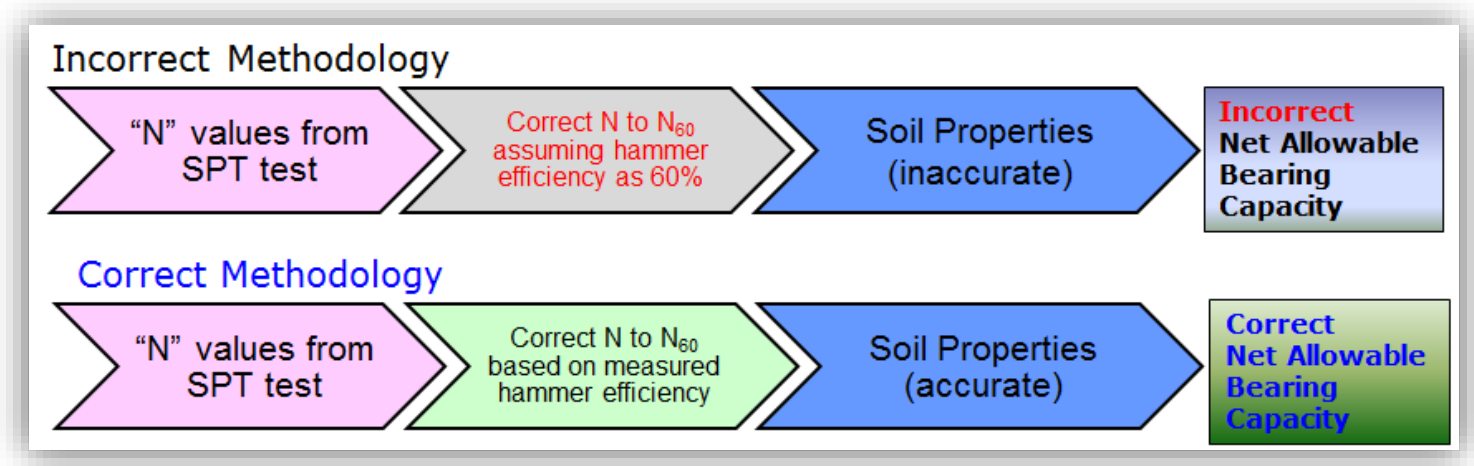

Fig. 6: Summary of SPT test data leading to NABC.

\section{Acknowledgments}

Authors would like to thank all the geotechnical contractors serving Saudi Aramco for their input in improving the SPT testing methodology in the Kingdom of Saudi Arabia by Energy Efficiency Calibration of all SPT hammers.

\section{References}

[1] ASTM D1586-11 Standard Test Method for Standard Penetration Test (SPT) and Split-Barrel Sampling of Soils.

[2] ASTM D4633 - Standard Test Method for Energy Measurement for Dynamic Penetrometers.

[3] BS EN ISO 22476-3:2005 +A1:2011, Geotechnical investigation and testing Field testing, Part 3: Standard penetration test.

[4] B. M. Das. Principles of Foundation Engineering, 7th ed., Cengage Learning.

[5] FHWA NHI-01-031 Subsurface Investigations - Geotechnical Site Characterization, Reference Manual, US. Department of Transportation Federal Highway Administration, 2002.

[6] FHWA NHI-06-088 Soils and Foundations - Volume I, Reference Manual, US. Department of Transportation Federal Highway Administration, 2006.

[7] FHWA NHI-06-089 Soils and Foundations - Volume II, Reference Manual, US. Department of Transportation Federal Highway Administration, 2006.

[8] J. B. Burland, M. C. Burbidge, "Settlement of Foundations on Sand and Gravel," in Proceedings of Institute of Civil Engineers, Part 1, vol. 7, pp. 1325-1381, 1985.

[9] R. B. Peck, W. E. Hanson, T. H. Thornburn, Foundation Engineering, 2nd ed. Wiley, New York, 1974. 